\title{
HACIA OPPIANO LICARIO
}

\author{
Por \\ ENRICO MARIO SANTĨ \\ Cornell University
}

Aun antes de la publicación en 1977 de Oppiano Licario, la novela póstuma de Lezama Lima, la crítica viene especulando sobre la relación del texto a la obra anterior del autor y, sobre todo, su vínculo con Paradiso (1966), su primera novela. ${ }^{1}$ La repentina muerte de Lezama (en agosto de 1976) ha ido avivando aún más estas preguntas ya que sugiere que el manuscrito de Oppiano quedó en estado trunco. Si añadimos a todo esto las consabidas dificultades de lectura con que siem pre nos reta una obra como la de Lezama y las dificultades de comunicación con La Habana, donde falleció el autor y aún reside su viuda, María Luisa Bautista de Lezama, se nos presenta acaso el misterio bibliográfico más intrincado de la reciente novela latinoamericana. No pretenderé en esta brevísima intervención hacer una lectura exhaustiva de los vínculos evidentes entre Paradiso y Oppiano Licario. Esa tarea, laboriosa pero imprescindible, habrá que hacerse con el debido tiempo y amplitud de que, lamentablemente, no disponemos hoy. Más útil y oportuno me ha parecido compartir los resultados de un viaje de investigación a La Habana que hice en junio de 1979 y durante el cual tuve el privilegio de estudiar el esbozo o esquema sobre el cual se basó Lezama en la redacción de Oppiano Licario. Mi ponencia, por tanto, se propone arrojar un poco de luz sobre estas cuestiones y se divide en dos partes: una, la más extensa, en que, primero, haré una descripción general de este esbozo y, después, pasaré a realizar un cotejo del mismo con la novela tal y como ha sido publicada. En la segunda parte, pasaré a hacer una serie de especulaciones críticas sobre la textualidad misma de la obra y de su posible lectura a la luz de estos descubrimientos.

Empecemos por lo más evidente: Oppiano Licario es la continuación de Paradiso y no una novela aparte y diferente, o mejor dicho, es la misma novela bajo otro título. Quiero decir que hemos de leer ese texto póstumo como el último fragmento (aunque no el fragmento último o final) de un texto más vasto. Ya en su correspondencia y en varias entrevistas contemporáneas

\footnotetext{
1 Hay dos ediciones de Oppiano Licario, una con prólogo de Manuel Moreno Fraginals (La Habana: Editorial Arte y Literatura, 1977) y otra mexicana. (México: Ediciones Era. 1977). La primera de éstas es más esmerada y contiene menos erratas.
} 
Leza ma había indicado esa continuación. Acaso la primera mención ex plícita sea la que aparece en carta de junio de 1966 a su hermana Eló́sa en la que expresa preocupación por las malinterpretaciones a que estaba siendo sometida Paradiso en ese momento: "si tengo tiempo", le escribe, "le añadiré un primer piso, para que todo quede resuelto y aclarado", 2 Ya se sabe que esa intención esclarecedora es lo que mueve todo el proyecto novelístico de Lezama, sobre todo en relación a su poesía y ensayística, como si fuera una alegoría de su concepción de la representación literaria. Pero no deja de ser revelador que el origen del texto póstumo sea esta "aclaración de una aclaración", por así decirlo, la construcción de un primer piso para facilitar el acceso a la "catedral". Un año antes de esta carta, en junio de 1965 y en otra carta a sus hermanas, el proyecto había aparecido como una lejana posibilidad ("tendrán que pasar algunos años"); pero no hace más que publicarse Paradiso para que esa segunda parte adquiera un sentido urgente. La misma urgencia, por cierto, aparecerá en otra carta al escultor Alfredo Lozano, en la que se describe el futuro texto como "un añadido para que el laberinto ascienda hacia su visibilidad". ${ }^{3}$

Pero si bien es evidente que Lezama proyectaba una continuación esencialmente homogénea con el texto anterior, también lo era que no podía ser una mera repetición. Si Paradiso había terminado, por ejemplo, con la muerte redentora de Oppiano Licario, la nueva novela tendrá, escribe, "su sombrío final". Tal descripción aparece en la misma carta del 65, y responde a una indagación epistolar de Eloísa en la que parece anticipar la muerte de José Cemí. ${ }^{4}$ Acaso sea ésta la razón (más allá del paralelo con la Divina Commedia) por la cual uno de los primeros títulos de la futura obra sea el de Inferno. En una entrevista con Ciro Bianchi Ross, Lezama le anticipa que él quería "acercarme a la auto-destrucción sacralizada de Foción. . . al caos que rodea a la innata eticidad de Fronesis, que ve las furias desatadas en su contorno... y al otro de la tríada, José Cemí, el obsesionado por la imagen". ${ }^{5}$ Ya sabemos que el texto de la novela (o el fragmento que tenemos) desmiente en parte este prognóstico tan sombrío, como también que el título dejó de ser Inferno para convertirse (después de barajar varias otras opciones como $L a$ vuelta [o La muerte] de Oppiano Licario, El reino de la imagen, Fronesis, etc.)

\footnotetext{
2 José Lezama Lima, Cartas (1939-1976), ed. de Eloísa Lezama Lima (Madrid: Editorial Origenes, 1979), p. 196.

${ }^{3}$ Cartas, pp. 172, 117.

${ }^{4}$ El texto reza: "No, Eloísa, no termina con el final terrible que [sic] tú aludes. termina con la muerte de Oppiano Licario..." p. 172.

${ }^{5}$ Recopilación de textos sobre José Lezama Lima. ed. de Pedro Simón (La Habana: Casa de las Américas, 1970).
} 
en el actual. (Sabemos también por lo demás, que Lezama llegó a publicar un anticipo de la novela con ese título en la revista Índice de Madrid en el año 68). ${ }^{6}$ De manera que el vínculo de Oppiano Licario con Paradiso, en su intención inicial al menos, queda claro: la continuación de la novela que llevará a los personajes a un final radicalmente sombrío y negativo. "En el Paradiso,"le confía a Bianchi Ross, "van naciendo las imágenes pero... en el Inferno estamos como quien se mira en un espejo, la muerte es la única respuesta".?

El esbozo de la novela que pude estudiar y transcribir durante mi visita a La Habana confirma en parte esta intención inicial. El esbozo ocupa unas siete páginas manuscritas por el propio Lezama que aparecen encabezadas por el título "Esbozo para el Inferno." Por ese título podemos deducir que se trata de un esbozo redactado antes de ser escrita la novela (es decir, no sobre la marcha de composición) o quizás inmediatamente después de la publicación de Paradiso, o sea entre los años 1966 y 1968. Además de ofrecer sintéticas descripciones de cada capítulo, el esbozo incluye notas al dorso de algunas páginas en las que se consignan nombres, alusiones literarias, situaciones narrativas y la manera de algunos personajes. Hemos de tener en cuenta, naturalmente que estamos ante un esbozo y por tanto que ello no supone una prefiguración exacta de la futura redacción. Pero dados el estado trunco del manuscrito y las circunstancias tan inciertas de su publicación, tal documento sí nos ayuda a conjeturar hasta qué punto pudo haber llegado la redacción de Lezama antes de que le sorprendiera la muerte. Máxime cuando tantos detalles que se consignan en el esbozo aparecen elaborados en la novela.

Acaso la diferencia más reveladora entre esbozo y novela sea la extensión del texto: mientras que la novela sólo tiene diez capítulos, el esbozo consigna trece (en realidad consigna catorce, pero sólo debido a que Lezama omite erróneamente el capítulo II). Las descripciones de cada uno de los capítulos por lo general sintetizan bastante fielmente la narración redactada, a unque no coinciden exactamente y la novela desarrolla (como es de esperar) muchos detalles que no aparecen en el esbozo. Por ejemplo, el esbozo omite toda mención de José Ramiro y Clara, la familia campesina, vecinos y empleados de los Fronesis en su finca de Villa Clara; tampoco se menciona el asesinato de José Ramiro, hijo, ni a Palmiro ni a Delfina, su futura esposa, todos los cuales aparecen en el primer capítulo. En su lugar, el esbozo consigna lo siguiente: "Niñez de Fronesis. Fronesis en París. Conversación sobre el aduanero Rousseau. Aparecen Champollión (pintor), Margaret McLearn, Sidi Galeb [sic], Mahommed. Evocación de OL a través de las reglas de San Benito".

f Indice, No. 232 (junio de 1968), pp. 26-28.

7 Recopilación, p. 28. 
Como sabemos, el primer capítulo de Oppiano Licario no incluye ni escenas de la niñez de Fronesis ni (a mi modesto entender) esa evocación a través de las reglas de San Benito. Lo que sí se describe-y ésta será la característica principal del esbozo-es el orden de los eventos de la trama y la aparición de los distintos personajes.

Resultaría demasiado laborioso realizar una descripción minuciosa de cada una de las diferencias entre las síntesis que aparecen en el esbozo y la redacción final. Quede esa tarea para un futuro trabajo. Sí quisiera apuntar lo que me parece más interesante: es decir, lo que, según el esbozo, se le quedó a Lezama, literalmente, "en el tintero". Probablemente el detalle más intrigante que encuentra el lector hacia el final del texto sea esa herida que recibe Fronesis en el capítulo IX y cuya noticia (por medio de un telegra ma enviado por Lucía, la amante de Fronesis) le causa un infarto cardíaco a su padre. Por lo que aparece redactado en el siguiente capítulo, el número $X$, que trata de otros temas completamente diferentes, podemos conjeturar que Lezama había querido dejar el desarrollo de esa historia en suspenso hasta llegar al capítulo siguiente, es decir, el número XI y que nunca llegó a redactar. Cuando cotejamos el esbozo descubrimos el por qué de ese suspenso. Si bien no existe una correspondencia exacta entre narración y esbozo, el esbozo explica, sin más detalles, que Fronesis será asesinado. El asesinato de Fronesis coincide con el regreso a Cuba de Lucía quien al participarle al Dr. Fronesis de su futuro nieto es rechazada por el mismo. Esa trágica y violenta muerte de Fronesis es paralela al otro acontecimiento que está consignado en el esbozo: Cidi Galeb viajará a La Habana "para escapar de la venganza de Mahommed", y es en La Habana donde conoce al Pelirrojo, ese ladronzuelo de cepillos chinos, con quien se alía "para chantajear a Foción". No obstante, es Foción quien, según el esbozo, matará a Cidi Galeb y después se suicidará él mismo lanzánd ose "desde lo alto del hotel". Las muertes paralelas de Fronesis y Foción, entonces son más que mera simetría lezamesca: sugieren que la auto-destrucción de Foción es el resultado de la muerte de Fronesis cuyo asesinato él parece vengar. De ahí que Cidi Galeb tenga que escapar "la venganza de Mahommed", quien, como sabemos, en la novela desarrolla una estrecha amistad con Fronesis parecida a la de Foción.

Pero a esas muertes paralelas le suceden también nacimientos paralelos, y son estos nacimientos los que, según el esbozo, proveen la clave de la novela. Si recordamos, en la novela tanto Lucía como Ynaca Eco están embarazadas de los hijos de Fronesis y Cemí, respectivamente. En el esbozo Lucía dará a luz un varón, mientras que Ynaca tendrá una hembra, hija de Cemí. Si contamos también a Focioncillo, el hijo de Foción, quien aparece mencionado en Paradiso y aparece por primera vez en el último capítulo de Oppiano Licario, comprobamos que cada uno de los tres personajes de la tríada (Fronesis, Cemí 
y Foción) tiene un vástago. En una entrevista inédita con Reynaldo González, realizada en 1971, Lezama describe el desarrollo de esta segunda generación de personajes: "Hacia el final hay un entrecruzamiento de los hijos de estos tres personajes, en que Cemí no quiere adoptar de ninguna manera la solución goethiana, es decir, el matrimonio del conocimiento-doctor Fausto--con la belleza-Elena de Troya-y que produce un monstruosillo, Euforión, que se precipita en el abismo, saltando y no logra sobrevivir. Procuro entonces otro emparejamiento entre la hija de Cemí, la hija de la imagen, que prefiere casarse con el hijo del loco, de Foción; es decir, la unión de la imagen con la locura". ${ }^{8}$ Lo que Lezama nunca llegó a explicarle a González es la manera en que Cemí llega a la decisión de impedir esta fatídica unión. Según el esbozo, Abatón Awalobit, el esposo de Ynaca Eco, ha conservado una copia de la Súmula, nunca infusa, de excepciones morfológicas, ese supuestamente fabuloso libro de Oppiano Licario, el cual se dedicó a componer durante toda su vida. En la novela Ynaca Eco le entrega el original de este libro a José Cemí, original cuya escritura las aguas de un ciclón habanero acaban borrando accidentalmente. Pero lo que además agrega el esbozo, y lo que hasta hoy ha sido un misterio, es el contenido de la Súmula, es decir, el tema del libro de Oppiano Licario. "En el escrito", dice el esbozo refieriéndose a la Súmula, "se consigna todo lo que ha sucedido en el Inferno, terminando con las bodas de la hija de Y naca Eco y Cemí, con el hijo de Fronesis y Lucía". El libro que escribe Oppiano, la Súmula, nunca infusa, de excepciones morfológicas, es la profecía del mismo libro que hemos estado leyendo, el libro que se nos presenta. Como ocurre con Las mil y una noches, o con un célebre manuscrito sánscrito confeccionado por un tal Melquíades, o como los personajes de la segunda parte (de la continuación) del Quijote, se suponía que los personajes de Lezama descubrieran su borgiana "magia parcial", su identidad con la "sobrenaturaleza" de la ficción. (De ahí, quizá, que Lezama haya optado, finalmente, por el título de Oppiano Licario, casi como dando a entender la coincidencia del nombre del libro con el del personaje ausente que cifra toda la novela.) No obstante, ségun el esbozo, la Súmula de Oppiano no podrá coincidir "de ninguna manera" con la novela que leemos, ya que es Cemí el que llega a leer la copia de la Súmula conservada por Abatón y así anticipa y frustra el fatídico enlace de su hija con el vástago de Fronesis: "Cemí impide", consigna el esbozo, "que su hija vaya a Europa para que no se encuentre con el hijo de Fronesis. Para evitar el mito de Eurofión... Se casan la hija de Cemí y de Ynaca con el hijo de Foción", es decir, "la unión de la imagen con la locura".

8 "Lezama Lima entre la magia y la infinitud", entrevista inédita por Reynaldo González, p. 22 del manuscrito. (La entrevista fue realizada, según González, "una mañana de enero de 1971".) 
Lo que se le "queda en el tintero"a Lezama son, pues, apenas tres capítulos. Y si, además del esbozo, hemos de creer sus declaraciones a González, la novela hubiera terminado con esas bodas alegóricas. En esa misma entrevista inédita Lezama declara que en 1971 calculaba un manuscrito de "unas cuatrocientas páginas, que añadidas a la primera parte darán unas setecientạs, ochocientas". 9 No sabemos a ciencia cierta si esas "páginas" se refieren a folios, cuartillas o páginas impresas. Por otro lado, Eloísa Lezama es testigo de la repetida aseveración de que faltaban apenas veinte o treinta páginas para terminar la novela, lo cual explicaría ese cambio que notamos en la propia correspondencia entre "el otro novelón" que prometía en carta de agosto de 1969 y lo que dice, siete años después, en otra de mayo de 1976: "No será tan extensa como Paradiso". ${ }^{10}$ Para adherirse al esbozo original se hubiera tenido que trazar no sólo el nacimiento sino también el desarrollo de la hija de Cemí e Ynaca, aún no nacida al final del texto que poseemos, como también el nacimiento del hijo de Fronesis y Lucía y el desarrollo de Focioncillo, ese mannekken pis criollo, quien al final del texto es apenas un niño. Pero, ¿podría haberse hecho todo esto en veinte o treinta páginas? ¿O acaso Lezama ideó otro final menos complejo?

Estas especulaciones se podrían multiplicar hasta el delirio, naturalmente, y una solución a la interpretación de Oppiano Licario sería simplemente el que realizáramos una lectura aislada que ignorase por completo el esbozo original. ${ }^{11}$ La critíca de Lezama, y de la novelística hispánica en general, tendrá que enfrentarse a las espinosas cuestiones que este texto nos plantea. Me refiero no sólo a las preguntas que he intentado contestar aquí sino a toda la problemática teórica que el texto implica. ¿Qué significa leer un fragmento? ¿Leemos ese texto a partir de su intención (el esbozo) o de su realización facticia (el fragmento)? Y si nos decidimos por uno o por otro (la tarea de toda crítica es el decidir, ya sea un sentido o la fijación filológica de un texto cualquiera), entonces cómo procedemos en nuestra lectura? Desde el otro lado del espejo, donde "la muerte es la única respuesta", Lezama nos sigue retando con sus conjuros:

\footnotetext{
9 Entrevista, p. 20.

${ }_{10}$ Cartas, pp. 26, 217, 285.

"Para tal intento de lectura véase la interesante reseña de Severo Sarduy, "Oppiano Licario de José Lezama Lima”, Vuelta, No. 18 (mayo de 1978), pp. 32-35.
} 
Yo quería rescatar los fragmentos de la noche y formaba una sustancia universal, comencé entonces a sumergir los dedos y los ojos en la noche, le soltaba las a marras a la barcaza.

La cita es del otro libro póstumo de Lezama: Fragmentos a su imán. ${ }^{12}$

\footnotetext{
12 Fragmentos a suimán, prólogo de Cintio Vitier (La Habana: Editorial Arte y Literatura, 1977), p. 71. Una versión más extensa de este trabajo, que incluirá un apéndice con la transcripción del esbozo de Oppiano Licario, se publicará en breve.
} 
